\section{Visões e práticas de mulheres vivendo com HIV/aids sobre reprodução, sexualidade e direitos}

\author{
Views and practices of women living with \\ HIV/AIDS on reproduction, sexuality, \\ and rights
}

\section{Visiones y prácticas de mujeres viviendo con $\mathrm{VIH} /$ sida sobre reproducción, sexualidad y derechos}

\section{Resumo}

O artigo analisa as visões e práticas sobre reprodução, sexualidade e direitos de mulheres vivendo com HIV/aids (MVHA). O estudo, de caráter qualitativo, teve, por base, entrevistas feitas em dois momentos, 2013 e 2018, com sete MVHA atendidas em serviços de referência em HIV/aids no Rio de Janeiro, Brasil. Foram investigadas opiniões e vivências sobre maternidade, interações afetivo-sexuais, feminismo e direitos sexuais e reprodutivos. Os achados revelam a percepção naturalizada das entrevistadas sobre o corpo feminino e a sua responsabilização acerca dos eventos da vida sexual e reprodutiva. Nota-se uma associação entre direito reprodutivo e direito de escolha da maternidade ou da participação dos pais na criação dos filhos. Quanto aos direitos sexuais, prevaleceu a concepção do direito de escolha da mulher (ou pessoa) diante das demandas, imposições ou violência para fazer sexo, incluindo o contexto das relações matrimonias. A conjuntura sociocultural mostrou-se mais determinante das práticas preventivas e trajetória reprodutiva do que a sorologia do HIV. Foi notado a capacidade das MVHA de remodelar práticas ligadas à rotina de cuidado com a família, à maternidade, a escolhas contraceptivas e ao exercício da sexualidade. Mas, as normas tradicionais de gênero se mostram fortemente nas suas dinâmicas familiares, e o alcance dessas transformações é mediado pelo contexto sociocultural e econômico. Assim, o menor acesso a bens simbólicos dos estratos populares, que caracteriza o universo das mulheres entrevistadas, compromete o acesso desses grupos a conquistas relativas à liberdade sexual è autonomia feminina.

Direitos Sexuais e Reprodutivos; Mulheres; AIDS; Gênero e Saúde
Jamille Maria Rodrigues Carvalho 1

Simone Souza Monteiro 2

doi: 10.1590/0102-311X00169720

\author{
Correspondência \\ J. M. R. Carvalho \\ Escola Nacional de Saúde Pública Sergio Arouca, Fundação \\ Oswaldo Cruz. \\ Rua Leopoldo Bulhões 1480, Rio de Janeiro, RJ \\ 21041-210, Brasil. \\ jamille.mrcarvalho@gmail.com \\ ${ }^{1}$ Escola Nacional de Saúde Pública Sergio Arouca, Fundação \\ Oswaldo Cruz, Rio de Janeiro, Brasil. \\ 2 Instituto Oswaldo Cruz, Fundação Oswaldo Cruz, Rio de \\ Janeiro, Brasil.
}


No início do século XX, era notável a ação de grupos de mulheres pelo reconhecimento do direito de autonomia do seu corpo e da reprodução, mas, somente na I Conferência Mundial de Direitos Humanos, em 1968, a liberdade de decidir sobre a reprodução foi considerada um direito de todas as pessoas 1. No Brasil, a partir da década de 1970 e do movimento de democratização, a luta pelo reconhecimento dos direitos reprodutivos, sobretudo das feministas, desempenha papel relevante para a inscrição de demandas pela igualdade de gênero no sistema jurídico do país 2 . Tal luta visa desvincular a abordagem demográfica no controle da natalidade, assegurando o direito de acesso a informações, meios e métodos anticoncepcionais e o direito de exercer a sexualidade e a reprodução livre de discriminação, imposição e violência 3 .

Corrêa \& Petchesky 4 (p. 149-50) argumentam que, para alcançar qualquer tipo de direito, especialmente para populações mais pobres e vulneráveis, é preciso garantir "uma política de bem-estar social, segurança pessoal e liberdade política", visando à eliminação de "injustiças raciais, étnicas, de gênero ou classe". Defendem uma compreensão de direitos que envolva o controle sobre o corpo, o poder de tomar decisões informadas e seguras sobre sua sexualidade e reprodução e a oportunidade de ter recursos para fomentar tais decisões. Em suma, assinalam que o discurso em torno dos direitos sexuais e reprodutivos deve abarcar os contextos de desigualdades associadas a hierarquias sociais, étnico-raciais, sexuais e de gênero.

Existem evidências acerca dos avanços na implementação de políticas associadas aos direitos sexuais e reprodutivos, incluindo o campo da saúde 5. Todavia, ainda há obstáculos para sua efetivação e consolidação. Importa aqui destacar o caso da assistência às mulheres vivendo com HIV/aids (MVHA). Na última década, a principal política nacional voltada para as mulheres centra-se na testagem durante o pré-natal e o parto, seguida do encaminhamento para tratamento dos casos positivos, visando à prevenção da transmissão vertical do HIV. Implementada desde 1997, essa política vem sendo atualizada frente aos avanços no tratamento antirretroviral 6.

A testagem do HIV no pré-natal e na assistência a grávidas soropositivas tem tido efeitos importantes na redução da transmissão vertical, em um cenário no qual 34,4\%, dos 966.058 casos de aids notificados no Brasil até junho de 2019, foram em mulheres 7 . Todavia, tal foco carece de uma abordagem de aspectos subjetivos, socioculturais e institucionais relacionados à vulnerabilidade social e aos direitos sexuais e reprodutivos das MVHA. Além da maior vulnerabilidade biológica da mulher ao HIV 8, sua infecção envolve desigualdades na distribuição de poder entre os gêneros e menor acesso a bens materiais e simbólicos entre aquelas pertencentes às camadas populares. Na atenção a mulheres soropositivas, faz-se necessário abordar suas condições de vida, redes de apoio, experiências de discriminação, desigualdades de gênero, desejo e práticas sexuais e preventivas.

A ênfase apenas na dimensão reprodutiva das MVHA reitera a função social de cuidado dos filhos e fomenta a submissão feminina, dificulta a autonomia das mulheres nas decisões reprodutivas e nos processos de empoderamento e amplia sua vulnerabilidade ao HIV. Informado por uma abordagem qualitativa, este trabalho pretende valorizar aspectos subjetivos e sociais ligados à infecção pelo HIV a partir da análise das práticas e visões acerca dos direitos sexuais e reprodutivos de MVHA, usuárias da rede pública de saúde, no Rio de Janeiro.

\section{Metodologia}

Abordar qualitativamente um tema é partir da premissa de que a realidade deve ser compreendida por meio da contemplação de sentimentos, representações e vivências dos sujeitos e o sentido que esses atribuem ao viver ${ }^{9}$. Tal enfoque se ajusta ao objetivo desse estudo, centrado na investigação de questões subjetivas, focalizando na interpretação das experiências dos indivíduos.

A pesquisa deriva do projeto Estigma, Gênero e Trajetórias Reprodutivas no Contexto da Epidemia de Aids no Rio de Janeiro, que envolveu observação participante nos serviços e entrevistas individuais com 29 usuárias gestantes, de 19 a 39 anos, e alguns dos seus parceiros 10. A partir do acesso ao banco de dados do projeto, o presente estudo contatou essas mulheres para uma nova entrevista, com o objetivo de conhecer as atuais condições de vida, a experiência do convívio com o HIV após a gestação e as implicações nas relações afetivo-sexuais e suas visões e práticas associadas aos direitos sexuais 
e reprodutivos. A realização de entrevistas em dois momentos distintos, 2013 e 2018, visou trazer a dimensão da temporalidade na análise da trajetória de vida de MVHA.

Inicialmente, o recrutamento das 29 entrevistadas em 2013 foi feito pelos telefones registrados à época, mas, após inúmeras tentativas, apenas um estava em uso. Em seguida, buscamos o perfil pessoal delas numa rede social, visando sinalizar a proposta da nova entrevista, mas identificamos apenas uma. Fomos, então, aos serviços em que elas eram acompanhadas em 2013. Em um deles, tivemos acesso ao prontuário de duas participantes que ainda eram acompanhadas nesse serviço. No outro, foi possível identificar nove mulheres. Das 12 mulheres contatadas, parte não foi encontrada, parte não revelou disponibilidade. Assim, após diversas tentativas, foi possível realizar uma nova entrevista com sete mulheres, em 2018, cujo perfil social encontra-se descrito no Quadro 1.

As novas entrevistas foram realizadas e gravadas pela autora J.M.R.C., mediante autorização, e ocorreram conforme a disponibilidade e preferência das MVHA: cinco foram feitas nos serviços em que elas faziam avaliações de rotina ou dispensação de terapia antirretroviral (TARV); uma em um shopping center e outra num serviço ambulatorial no qual a participante é acompanhada. As entrevistas abordaram os seguintes temas: cotidiano e condições de vida; maternidade e reprodução; prevenção de infecções sexualmente transmissíveis (IST)/aids e interações afetivo-sexuais.

As sete entrevistas foram categorizadas segundo as etapas definidas pela análise de conteúdo 11,12. $\mathrm{Na}$ classificação dos dados, buscou-se identificar os núcleos de sentido que emergiam nas falas das mulheres. Uma síntese interpretativa de cada categoria foi realizada para nortear a discussão e relacionar os achados com a teoria e os resultados de outros estudos. Esse processo resultou na reunião de categorias, como: rotina e rede de apoio; vivência da maternidade; uso de métodos contraceptivos; assistência em saúde; educação sexual; convivência com HIV/aids; feminismo e interações afetivosexuais. Neste artigo, optou-se por analisar as categorias relativas à vivência da maternidade, a interações afetivo-sexuais, ao feminismo e aos direitos.

A pesquisa está de acordo com os princípios da Resolução no 466/2012 do Conselho Nacional de Saúde (CNS), tendo sido aprovada pelo Comitê de Ética em Pesquisa da Escola Nacional de Saúde Pública Sergio Arouca/Fundação Oswaldo Cruz (CAAE 88316218.8.0000.5240).

\section{Quadro 1}

Caracterização das mulheres vivendo com HIV/aids entrevistadas em 2018.

\begin{tabular}{|c|c|c|c|c|c|c|c|}
\hline Nomes (fictícios) & Idade (anos) & $\begin{array}{c}\text { Raça/Cor } \\
\text { (autodeclarada) }\end{array}$ & Estado civil & Filhos & Ocupação & $\begin{array}{c}\text { Renda (salários } \\
\text { mínimos) * }\end{array}$ & $\begin{array}{c}\text { Diagnóstico do } \\
\text { parceiro }\end{array}$ \\
\hline Florbela & 25 & Parda & Solteira & 1 & Desempregada & Sem renda própria & Soronegativo \\
\hline Clarice & 40 & Parda & União estável & 4 & Comerciante & 2 & Soropositivo \\
\hline Carolina & 44 & Negra & Casada & 7 & Do lar & Sem renda própria & Soropositivo \\
\hline Cecília & 44 & Negra & União estável & 1 & Estoquista & 2 & Soronegativo \\
\hline Ângela & 29 & Parda & União estável & 1 & $\begin{array}{c}\text { Auxiliar de } \\
\text { serviços gerais }\end{array}$ & 1,5 & Soronegativo \\
\hline Jane & 44 & Parda & Casada & 5 & $\begin{array}{l}\text { Cuidadora de } \\
\text { idosos }\end{array}$ & 2 & Soronegativo \\
\hline Virgínia & 31 & Parda & União estável & 1 & Podóloga & 1,5 & Soronegativo \\
\hline
\end{tabular}

Fonte: elaboração própria.

* Em 2018, período das entrevistas, o salário mínimo era de R\$954,00. Segundo classificação do Critério por Faixas de Salário Mínimo (Instituto Brasileiro de Geografia e Estatística), são pertencentes às classes econômicas D e E (https://thiagorodrigo.com.br/artigo/faixas-salariais-classe-social-abep-ibge/ amp/, acessado em 15/Jun/2020). 


\section{Resultados e discussão}

\section{Os sentidos da maternidade e do HIV}

Ao lembrarem da gravidez há cinco anos, as entrevistadas reconhecem que o acesso ao acompanhamento do serviço de saúde especializado possibilitou a não infecção dos filhos e mudou o sentido da fatalidade da aids. Embora afirmem que esse processo foi desgastante e preocupante, o HIV não foi determinante na decisão de encerrar a carreira reprodutiva. Das sete entrevistadas em 2018, uma (Carolina) teve outro filho, e as outras apontaram o contexto socioeconômico desfavorável e as responsabilidades como os principais fatores para não desejarem outras gestações. Seus relatos indicam que a função da maternidade é naturalizada em suas trajetórias de vida: "Quando eu era mais nova não pensava não. Mas, tem uma época que a gente sente falta, entendeu? Você sente a necessidade de ser mãe. Antes dos 27, eu nem pensava. Eu achava ser mãe uma coisa muito assustadora" (Cecília, 44 anos).

A literatura tem descrito o estabelecimento das formas convencionais da família como uma das instituições mais importantes da estrutura social e como o vínculo mãe-filho é valorizado como constitutivo delas. Reafirma-se assim o papel da mulher mãe como um caminho natural e inerente à mulher. Não ter a maternidade como um desejo de vida pode desencadear julgamentos numa sociedade em que a maternidade é culturalmente valorizada como importante atributo da identidade feminina 13 .

Como aponta Brandão 14 (p. 68): "aos 'direitos sexuais e reprodutivos', propriamente ditos, a percepção é ainda muito tênue (...) pela dificuldade que ainda encontramos para desconstruir a tão arraigada concepção do corpo humano, sobretudo do corpo feminino, como um ente da natureza". Barbosa \& Knauth 15 igualmente destacam que a família se constitui num dos principais valores do sistema simbólico, sendo fundamental na determinação da identidade social particularmente nas camadas populares. A naturalização do papel materno como um destino engendra uma pressão social para que aconteça e acaba por resguardar às mulheres um valor restrito a essa definição, tornando-as menos do que cidadãs 16 .

Ao serem indagadas sobre o planejamento da maternidade, as entrevistadas disseram que a mulher deveria programar a gravidez. Entre 25 e 30 anos, foi referido como o momento mais recomendado para engravidar, considerando que, nessa fase, em geral, as mulheres já estão em um relacionamento estável, com emprego e mais estrutura psicológica. Contudo, as condições materiais de existência das entrevistadas não favoreceram a realização desses ideais. Para boa parte delas, as gestações ocorreram sem esse planejamento. Florbela, Virgínia e Ângela não gozavam de um relacionamento estável quando descobriram a gravidez. Para Carolina e Jane, a oportunidade de formar uma família surgiu como um escape para sair da casa dos pais num contexto de pobreza e vulnerabilidade, visando à melhoria das condições de vida e à ascensão social: "A minha vida foi muito triste, muito pobre quando eu era criança, então, quando eu fiz 17 anos, pintou uma pessoa que gostava de mim, se propôs a me ajudar, a me dar uma vida melhor, eu fui morar com essa pessoa" (Jane, 44 anos).

As diferenças entre o momento definido como ideal e a realidade das entrevistadas podem ser compreendidas pelo peso da escolaridade e das condições socioeconômicas na determinação dos comportamentos reprodutivos e de organização das famílias. Segundo dados nacionais 17,18 , tem havido aumento no uso de métodos contraceptivos e redução da fertilidade das brasileiras. Todavia, a perspectiva de planejamento da maternidade é mais comum entre mulheres de classe média/alta, frente ao maior acesso a bens materiais e simbólicos, ao conhecimento e a recursos para definir quando e se deseja ter filhos e ao investimento na carreira profissional.

Ainda sobre as decisões e práticas reprodutivas, as participantes defendem o direito de escolha das mulheres de serem mães ou não; uma tomada de decisão descrita como pessoal, que deve ser influenciada apenas pelo marido. Contudo, elas afirmam que, a partir do momento em que a mulher opta por não ser mãe, ela deve se responsabilizar pela prevenção da gravidez, frente à ampla oferta de métodos contraceptivos disponíveis. Como ilustra o relato, caso a gravidez aconteça, a mulher deve assumi-la: "Se você foi mulher suficiente para chegar até lá, você tem que ser mulher suficiente para você parir a sua filha. Para colocar no mundo. A não ser uma pessoa que esteja determinada a não ter filho e a se prevenir de tudo quanto é forma, é diferente" (Ângela, 29 anos).

Como destacado em estudos prévios, existe uma obrigação moral de exercitar o cuidado e, ao mesmo tempo, evitar danos às pessoas; "uma preponderância do valor 'família' em relação à premissa da autonomia individual feminina" 14 (p. 62). Essa função social atribuída à mulher está envolta de uma 
romantização do sacrifício em prol do outro, em que o feminino se alinha a características de cuidado, devotamento e capacidade de renúncia. No caso das gestantes soropositivas, esse zelo é acrescido pelo cuidado com a saúde do bebê que envolve um universo totalmente novo de prescrições e condutas sobre o uso da medicação (delas e do bebê), a rotina de exames e as indicações do tipo de parto. Ademais, elas precisam lidar com a proibição da amamentação, vivenciada com bastante sofrimento, como ilustra o relato de Ângela, 29 anos: "Foi ruim. Essa parte eu chorei. Foi bem difícil. Porque era a minha primeira filha e eu não pude amamentar, tive que tomar remédio para secar (...) essa foi a parte mais difícil, quando ele [médico] me falou que eu não ia poder amamentar, o restante não [choro]”.

A representação usual da maternidade está intimamente ligada à responsabilidade de cuidar do filho, como uma expressão do amor materno. Durante a gravidez, o sentido principal de tomar o medicamento é evitar a transmissão do HIV para o bebê. Após a gestação, a necessidade de estar bem de saúde para conseguir cuidar da criança influencia a adesão ao tratamento. Um cuidado de si que incide sobre o cuidado do outro, em um imperativo para que elas assumam um lugar de vigilância constante sobre suas vidas 19 . Isso não significa que não existam desafios na adesão, contudo, os significados atribuídos à maternidade e os valores positivos que ela representa para as mulheres favorecem a responsabilidade pela saúde dos filhos: "Nunca parei, mas teve uma época da minha vida em que eu queria parar sim que foi quase no finalzinho da minha gravidez dele, de 8 pra 9 meses. Porque meus pais não aceitaram no início a gravidez. [O que te faz continuar o tratamento?] O medo de ficar doente. Por ele. Porque se eu ficar doente, quem vai cuidar dele? Eu não vou ter os meus pais pro resto da vida, ele só tem 5 anos, então, isso me dá a maior força" (Florbela, 25 anos).

Convém salientar que, após cinco anos da gestação no contexto do HIV, o atendimento das mulheres entrevistadas nos serviços de acompanhamento mantém-se focado na necessidade de adesão ao tratamento e no uso de preservativo, além dos exames de monitoramento da carga viral. O receio da exposição ao estigma da aids e os direitos sexuais e reprodutivos no âmbito das relações conjugais não são abordados pelos profissionais do serviço 20.

As opiniões das entrevistadas sobre o aborto reiteram a noção de responsabilização da mulher pela anticoncepção. Todas declararam que são contra o aborto. Predomina uma correlação entre o controle da sexualidade das mulheres e seu papel na reprodução, refletido no entendimento de que é possível evitar a gravidez indesejada de muitas formas. Como já dito, elas afirmam que há uma variedade de métodos contraceptivos disponíveis em unidades de saúde ou de fácil acesso; sendo assim, engravidar sem planejamento é visto como descuido e irresponsabilidade. É dever da mulher assumir e lidar com as consequências dos seus atos.

A valorização da maternidade e a objetificação feminina negam às mulheres o direito à autonomia 16. O fato de ser dona do corpo no qual o feto se desenvolve gera o dever de arcar com as consequências da sua "irresponsabilidade", enquanto há um apagamento do homem, comumente retirado dessa obrigação. Paradoxalmente, ser dona do corpo em que a fecundação ocorre não lhe dá o direito de escolher manter ou não a gravidez. A dádiva de gerar um filho é, na verdade, uma obrigação. Essa responsabilização envolve um mecanismo de culpa na relação mulher como mãe e feto, fruto da punição pelo prazer sexual obtido, que colabora para a manutenção da gestação. Segundo Biroli 16, a autonomia de dispor sobre o próprio corpo é uma das bases para o acesso à cidadania e engloba o direito de decidir sobre manter ou não uma gravidez; que faz parte dos direitos individuais básicos. Impor às mulheres limitações nesse direito é alargar as assimetrias de gênero.

Além de fundamentos religiosos e concepções pró-vida, o aborto tem profunda relação com a desigualdade social. Classe e raça são variáveis que vão diferenciar a autonomia reprodutiva das mulheres de acordo com sua posição social, em um contexto de criminalização do aborto no país. Ilustra essa situação o fato de as mortes decorrentes de procedimentos clandestinos do aborto atingirem predominantemente mulheres de baixo poder aquisitivo ${ }^{21}$. Para Domingues et al. ${ }^{18}$, a manutenção da gestação entre mulheres de menor escolaridade guarda relação tanto com acesso mais reduzido a métodos de interrupção quanto ao peso simbólico da maternidade.

O fato de a condição sorológica não ter desempenhado papel preponderante nas escolhas reprodutivas das MVHA, nem na utilização do aborto como forma de regulação da fertilidade, pode ter relação com o aumento da sobrevida de pessoas vivendo com HIV/aids, redução da transmissão vertical e ampliação do acesso a métodos contraceptivos, como indicado pelas participantes 18 . Contudo, ainda existem inúmeras barreiras no que concerne à saúde sexual e reprodutiva das MVHA. Segundo 
estudo recente na América Latina 22, elas continuam sofrendo discriminações e violações nas suas necessidades contraceptivas, tendo maior preponderância nos riscos de gravidez não planejada, abortos induzidos, esterilização no pós-parto imediato, de violência sexual e institucional, do que mulheres não infectadas pelo HIV.

\section{Sexualidade e práticas contraceptivas no contexto do HIV}

Nos relatos sobre a representação do casamento, as entrevistadas demonstram uma busca por relações mais horizontais, de parceria e troca com os companheiros. No entanto, a internalização dos papéis tradicionais de gênero e o modelo de família tradicional, por vezes, obstaculizam o alcance dessa vivência. A percepção naturalizada do corpo dificulta a apreensão da sexualidade e da reprodução como instâncias independentes e de gestão do próprio corpo e da saúde na perspectiva das formulações de direitos sexuais e reprodutivos. Para algumas, o casamento é bastante vinculado à função social da mulher de cuidado das tarefas domésticas, filhos e marido. Há uma sobreposição do papel de dona de casa e, principalmente, no que concerne à ideia de servidão sexual. Clarice (40 anos) compartilha como isso se dá em sua relação: "Eu tento na hora do sexo ser o mais natural possível, entendeu? 'Pode? Pode. Vamos fazer? Vamos.' Sempre concordando com tudo, para evitar problema. Porque se eu não for, o problema aumenta. Então, para evitar problema... Das últimas vezes, é sempre assim [risos]. Faz por obrigação (...) é a obrigação da mulher né? [risos]... Pra evitar problema... quer? Então toma, vai, acabou!".

A inserção da mulher nos relacionamentos apresenta-se ainda mediada pelo uso do corpo, seja atraindo o companheiro no início do envolvimento, seja "cumprindo suas obrigações para evitar o pior" em sua família. As marcas de gênero se fazem presentes ao conceberem o desejo sexual dos companheiros como uma necessidade fisiológica que deve ser atendida por elas, em seu "papel de mulher". Dessa forma, recusar a investida do marido pode sinalizar uma ruptura no acordo conjugal e trazer prejuízos ao casamento e à dinâmica familiar. Muitas vezes, tomar essa decisão envolve um alto custo para parte das mulheres que sentem que não estão cumprindo com suas "obrigações" 14.

Da mesma forma, como já assinalado, a contracepção é vista como responsabilidade exclusiva da mulher, no intuito de controlar a prole e evitar a gravidez não planejada, num cunho normativo apoiado nas representações tradicionais de gênero, em que o masculino está associado à sexualidade ativa, e o feminino, à reprodução. Questões da vida reprodutiva se fundem com questões familiares e domésticas e compõem o escopo da vida privada destinada à mulher. A vivência da sexualidade feminina fica então atrelada à função de contracepção.

$\mathrm{Na}$ experiência das participantes, no início da vida sexual, a pílula é a primeira escolha, sendo o método mais utilizado e conhecido para evitar a gravidez. Há uma naturalização dessa função como um destino da mulher, geralmente orientada pela mãe, amigas ou primas já iniciadas nesse processo. A maioria busca uma combinação de métodos, quase sempre a camisinha e a pílula. Mas, o uso de ambos é irregular, pela resistência dos parceiros à camisinha e pela dificuldade delas de adesão aos anticoncepcionais hormonais. Não foi registrada uma preocupação com infecções sexualmente transmissíveis. Como assinala Knauth et al. ${ }^{23}$, por meio do pré-natal ou pelo adoecimento, as mulheres revelam a presença do HIV e tornam-se, muitas vezes, a "porta de entrada" dos homens heterossexuais nos serviços de saúde; ou seja, assumem um papel ativo na promoção da saúde masculina.

Algumas entrevistadas passaram a usar o preservativo de forma mais frequente após o diagnóstico de HIV, diante do grande medo de infectar o parceiro sorodiscordante. Como indicado no Quadro 1, das sete entrevistadas, cinco tinham companheiros soronegativos. Todavia, em alguns casos, o uso continuou irregular ou se tornou ausente com o passar do tempo e a convivência com HIV. Cabe salientar que a ausência de sintomas e a carga indetectável das parceiras, em decorrência do tratamento, fomentam certa despreocupação dos parceiros com a transmissão do HIV e sugerem uma banalização da doença. O relato de Jane (44 anos) retrata como algumas buscam comprovar o baixo risco de infecção para que o parceiro se mantenha resguardado ao rejeitar o uso do preservativo: "Toda vez que eu venho ao médico, eu peço um exame pra doutora imprimir, pra eu poder mostrar pra ele então como está indetectável (...) Então ele falou, 'se você tem 0 risco de me infectar, eu vou ficar usando preservativo pra quêe’ Até porque ele nunca gostou, ele não se adapta. Ele não tem ereção com preservativo".

Em suma, cinco anos após a gestação no contexto da descoberta do HIV, a responsabilização pela contracepção continua sendo da mulher. A decisão de usar ou não o preservativo está, em geral, 
centralizada na figura masculina, tanto antes como após a descoberta do HIV. Fato que demanda uma reorganização da vida reprodutiva para as mulheres, que precisam estar em constante negociação ou se utilizar de outras formas para continuar realizando o controle da prole. Tais dados foram atestados pela análise de Fraga 20 sobre práticas reprodutivas e preventivas entre casais grávidos vivendo com HIV das camadas populares. Segundo a autora, as decisões reprodutivas do casal são influenciadas pela predominância dos papéis tradicionais de gênero nesse segmento social; bem como pela percepção das MVHA de que a permanência do companheiro, após a descoberta da soropositividade delas, é uma grande prova de amor, principalmente se ele for soronegativo. Tais fatores, somado ao elo de confiança estabelecido com o companheiro, dificultam a negociação e o uso consistente de medidas preventivas. Barbosa \& Knauth 15 igualmente apontam que os contextos sociais e culturais são mais determinantes nas práticas preventivas do que o próprio conhecimento do estado sorológico.

Assim, obstáculos potenciais à adoção de métodos contraceptivos devem ser alvo do cuidado em saúde para promover autonomia reprodutiva às MVHA. A integração do planejamento familiar aos cuidados com o HIV fornece um modelo para aumentar a acessibilidade e potencialmente melhorar os resultados da saúde reprodutiva 24 .

\section{Direitos sexuais e reprodutivos e feminismo na perspectiva das entrevistadas}

Como indicado, direitos sexuais e reprodutivos são considerados direitos humanos fundamentais e necessários para o pleno exercício da cidadania. $\mathrm{O}$ uso da expressão tem, por base, as proposições dos movimentos de mulheres que lutavam pelo direito ao próprio corpo e por uma ampliação da noção de saúde reprodutiva, capaz de abarcar o aborto, o acesso à contracepção, o debate sobre a medicalização do corpo feminino e o uso abusivo de tecnologia, a partir do respeito à integridade corporal das mulheres 5. Apesar de sua incorporação em documentos oficiais e do entendimento de que são garantias necessárias para se alcançar a igualdade de gênero e a justiça social, o conceito ainda é pouco difundido nos contextos das instituições de educação e de saúde. Ainda que muitos avanços tenham ocorrido, relacionados à liberdade sexual feminina, ao aborto, à reprodução assistida e a métodos contraceptivos, o viés conservador, moralista e culpabilizador dos comportamentos femininos persiste e é atualizado.

Ao investigar o entendimento das participantes sobre direitos sexuais e reprodutivos, pretendíamos conhecer os significados dados aos termos, que poderiam ser complementados pelos relatos acerca dos assuntos abordados na entrevista, referidos acima. Nos depoimentos sobre direitos reprodutivos, nota-se uma associação com o direito de escolha da maternidade como ilustram as seguintes falas: "É o direito de você poder escolher se você quer ser mãe ou não" (Clarice, 40 anos); "Já ouvi falar, mas não lembro... será que é o direito da mulher ser mãe? Reproduzir?" (Jane, 44 anos). Com relação à noção de direitos sexuais, prevaleceu a noção do direito de escolha da mulher (ou das pessoas) diante das demandas, imposições ou violência para fazer sexo, incluindo o contexto das relações matrimonias: "Eu acho que é a liberdade de você poder dizer não quando você não está a fim. E a parceira ou o parceiro tem que te respeitar. Porque tem homem que acha que a mulher tem que servir quando ele está a fim" (Cecília, 40 anos).

Depreendemos que, ao serem expostas aos discursos feministas e às mudanças normativas e jurídicas no campo da sexualidade e do gênero, propagados pelo debate e ações públicas, algumas mulheres sentem mais confiança e possibilidade de serem ajudadas em situações de vulnerabilidade. Contudo, como argumentam Corrêa \& Petchesky 4, para que esses direitos sejam efetivados, é necessário um contexto geral de bem-estar social e cidadania, pouco assegurado nos estratos mais populares urbanos. Ademais, tais discursos encontram resistências e são contrapostos por visões críticas e conservadoras. Ou seja, o entendimento de maior naturalização dos papéis sociais tradicionais atribuídos às mulheres, como a reprodução, necessita considerar as condições materiais e simbólicas desse grupo ao longo da vida e o contexto sociocultural e político.

As normatizações impostas ao corpo feminino estão no centro da proposta feminista de descontruir as representações sociais sobre o corpo da mulher como sexuado e reprodutor, objetivando democratizar e tornar mais igualitária tanto a esfera pública quanto a privada do tecido social 25 . Visando conhecer se esse contexto era familiar às participantes do estudo, indagamos sobre seus entendimentos do que era feminismo. As respostas sugerem uma não familiaridade com o conceito de feminismo e um desconhecimento do movimento de mulheres, exemplificados nos relatos: "Eu tenho 
ouvido muito na televisão, que é a matança de mulheres né? As pessoas... não é isso? O homem que não aceita separação" (Jane, 44 anos); "Eu não tenho como te explicar, não sei do que se trata. Eu já ouvi falar assim, lá longe. Eu acho que numa novela" (Virgínia, 31 anos).

Todavia, as pautas feministas as alcançaram em algum nível, sendo mediadas, em parte, pelos meios de comunicação ao discutirem sobre a igualdade de direitos nas relações, a liberdade sexual e o trabalho como forma de autonomia da mulher. Elas reconhecem a existência de machismo no Brasil, mesmo em seus companheiros e até em outras mulheres, numa perspectiva ligada ao cerceamento de direitos, sejam eles o de vestir o que deseja, de expressar uma opinião diferente do parceiro ou da possibilidade de inserção no mercado de trabalho.

Mesmo reconhecendo e validando todas as conquistas alcançadas pelo movimento feminista, materializadas inclusive em marcos e políticas nacionais e internacionais, os achados indicam a perpetuação de alguns impasses na incorporação da formulação feminista de direitos sexuais e reprodutivos nesse universo sociocultural. Os dados sugerem que ainda prevalece uma naturalização do controle sobre as mulheres, como se a norma da vida feminina fosse essa, pois é a realidade que conhecem e com a qual passaram pelo processo de socialização. Ou seja, há uma discrepância e um desencontro entre os pressupostos teóricos e políticos feministas e a vivência e a percepção cotidianas que as mulheres oriundas dos estratos populares urbanos (ainda) mantêm da condição feminina e da vida conjugal 14 .

As trajetórias de vida das mulheres entrevistadas antes do diagnóstico do HIV são marcadas por processos de desigualdades de gênero e exclusão social, como já assinalado 10, não havendo mobilidade social nos últimos anos, como indica o perfil no Quadro 1. Tais fatores, somados ao menor envolvimento político das mulheres no enfrentamento da epidemia e à persistência do estigma 26, dificultam a convivência com a infecção e a luta pelos direitos sexuais e reprodutivos. Ademais, os direitos sexuais e reprodutivos das MVHA não têm sido contemplados na agenda governamental 10,27. As conexões entre vulnerabilidade e a infecção pelo HIV demandam novos olhares sobre as políticas públicas e ações em saúde comprometidas com um projeto de emancipação e redução das desigualdades, já que ambas as situações são expressões das assimetrias de gênero 28 .

\section{Considerações finais}

Os principais achados deste estudo estão relacionados às evidências sobre a percepção naturalizada das mulheres investigadas acerca do corpo feminino e da sua responsabilização e culpabilização em relação aos eventos da vida sexual e reprodutiva. Foi possível reconhecer a capacidade que elas têm de tangenciar certos padrões tradicionais de gênero e remodelar práticas ligadas à rotina de cuidado com a família, à maternidade, a escolhas de métodos contraceptivos e ao exercício da sexualidade. Contudo, as normas tradicionais de gênero se mostram fortemente instaladas nas suas dinâmicas familiares.

Entende-se que as escolhas femininas nos âmbitos da sexualidade e reprodução, como direitos individuais, dão-se a partir do contexto dos direitos sociais. De igual modo, a liberdade de escolha depende do acesso a condições para que se possa tomar uma decisão consciente. Assim, a despeito dos progressos no campo da liberdade sexual e da autonomia feminina sobre seus corpos e escolhas reprodutivas, o alcance dessas transformações na vida das pessoas é mediado pelo contexto sociocultural e econômico, estabelecendo, assim, uma correlação entre saúde sexual e reprodutiva, cidadania das mulheres e as políticas de desenvolvimento. Desse modo, o menor acesso a bens simbólicos dos estratos populares, que caracteriza o universo das mulheres entrevistadas no estudo, compromete o acesso desses grupos a essas conquistas. Soma-se a isso a regulação realizada por parte do Estado, por meio de Projetos de Lei e de Emendas Constitucionais em tramitação, que envolvem as decisões reprodutivas como, por exemplo, a criminalização do aborto.

As conexões entre vulnerabilidade, violência e gênero ainda impactam nas condições de saúde das mulheres, principalmente na saúde sexual e reprodutiva, como é o caso da infecção de HIV/aids. Além disso, as ingerências se dão no cuidado prestado às MVHA, sobretudo quando essa mulher está gestante. Questões relacionadas aos direitos sexuais e reprodutivos ficam encobertas diante da prioridade de evitar a transmissão vertical. Não que essa preocupação não seja válida e necessária, mas o apagamento da mulher como ser sexual independente do seu papel de mãe acarreta desdobramentos 
na vivência das relações afetivas, na vida sexual e na autonomia de decisões reprodutivas, tendo ainda as repercussões da infecção pelo HIV perpassando esse quadro. Como afirmam Barbosa \& Knauth 15, toda mudança na prática médica para reduzir a transmissão vertical modela, em algum grau, as decisões reprodutivas das mulheres HIV positivo, demandando atenção das políticas públicas.

A mudança desse cenário é um processo longo, que envolve transformações culturais associadas às desigualdades sociais, de gênero e étnico-raciais, a partir de ações de diversos atores sociais e instituições, inclusive os do setor saúde. O atual contexto de retrocessos que o país tem vivenciado, caracterizado pelo recrudescimento de visões conservadoras e pelo impacto da pandemia de COVID-19, aponta para a importância da reafirmação da garantia dos direitos sexuais e reprodutivos. As ameaças ao exercício dessa autonomia tornam esse debate atual e necessário para se alcançar igualdade, desenvolvimento e justiça social. Mesmo em um cenário de desafios, a saúde precisa se constituir como um dos espaços de enfrentamento das desigualdades de gênero. Como apontam Corrêa \& Petchesky 4 , o corpo existe em um universo socialmente mediado. É necessário considerar essa modelagem e os limites que a assistência em saúde é capaz de abarcar, mas não se pode invisibilizar o seu lugar nessa luta.

Consideramos que os achados descritos podem contribuir para melhoria do atendimento às MVHA e ações na rede pública de saúde em âmbito local, ampliando a reflexão sobre a sexualidade desse grupo, as formas de prevenção, como lidar com o corpo, com o desejo do parceiro e a importância de se incentivar campanhas e programas de saúde que visem esse público em suas especificidades, além de destacar como questões de ordem subjetiva e social influenciam na eficiência de políticas e do cuidado em saúde. Temos ciência de que o trabalho possui limites, como o número restrito de entrevistas, apesar dos esforços de contato. No entanto, consideramos que os achados possibilitaram avanços na discussão da temática proposta e abriram perspectivas para investigações futuras.

\section{Colaboradores}

J. M. R. Carvalho foi responsável pelo desenvolvimento do estudo, pela análise dos dados e pela redação do artigo. S. S. Monteiro participou da concepção do estudo, orientação metodológica, revisão da análise dos dados e redação do artigo.

\section{Informações adicionais}

ORCID: Jamille Maria Rodrigues Carvalho (00000003-3605-1021); Simone Souza Monteiro (00000003-2009-1790).

\section{Agradecimentos}

O presente trabalho foi realizado com o apoio da Coordenação de Aperfeiçoamento de Pessoal de Nível Superior (CAPES).

\section{Referências}

1. Toneli MJF. Direitos sexuais e reprodutivos: algumas considerações para auxiliar a pensar o lugar da psicologia e sua produção teórica sobre a adolescência. Psicol Soc 2004; 16:151-60.

2. Carrara S, Vianna A. Os direitos sexuais e reprodutivos no Brasil a partir da Constituição Cidadã. In: Oliven RG, Ridenti M, Brandão GM, organizadores. A Constituição de 1988 na vida brasileira. São Paulo: Editora Hucitec; 2008. p. 334-59.

3. Departamento de Atenção Básica, Secretaria de Atenção à Saúde, Ministério da Saúde. Saúde sexual e saúde reprodutiva. Brasília: Ministério da Saúde; 2013. (Cadernos de Atenção Básica, 26).

4. Correa S, Petchesky R. Direitos sexuais e reprodutivos: uma perspectiva feminista. Physis (Rio J.) 1996; 6:147-77. 
5. Villela W, Monteiro S. Atenção à saúde das mulheres: historicizando conceitos e práticas. In: Villela W, Monteiro S, organizadores. Gênero e saúde: Programa Saúde da Família em questão. Rio de Janeiro: Associação Brasileira de Saúde Coletiva/Fundo de População das Nações Unidas; 2005. p. 15-31.

6. Programa Nacional de DST e Aids, Ministério da Saúde. Protocolo para a prevenção de transmissão vertical de HIV e sífilis. Brasília: Ministério da Saúde; 2007.

7. Ministério da Saúde. Boletim Epidemiológico HIV/Aids 2019; (número especial).

8. Rodrigues CS. A feminização do HIV/AIDS no município de Salvador/Bahia sob a perspectiva de mulheres infectadas: uma questão de gênero [Dissertação de Mestrado]. Salvador: Universidade Católica de Salvador; 2013.

9. Günther H. Pesquisa qualitativa versus pesquisa quantitativa: esta é a questão? Psicol Teor Pesqui 2006; 22:201-10.

10. Monteiro S, Villela W, Fraga L, Soares P, Pinho A. The dynamics of the production of AIDSrelated stigma among pregnant women living with HIV/AIDS in Rio de Janeiro, Brazil. Cad Saúde Pública 2016; 32:e00122215.

11. Silva CR, Gobbi BC, Simão AA. O uso da análise de conteúdo como uma ferramenta para a pesquisa qualitativa: descrição e aplicação do método. Organizações Rurais \& Agroindustriais 2005; 7:70-81.

12. Minayo MCS. O desafio do conhecimento: pesquisa qualitativa em saúde. $5 \underline{a}$ Ed. Rio de Janeiro: Associação Brasileira de Saúde Coletiva/São Paulo: Editora Hucitec; 1998.

13. Heilborn ML, Portella AP, Brandão ER, Cabral CS; Grupo CONPRuSUS. Assistência em contracepção e planejamento reprodutivo na perspectiva de usuárias de três unidades do Sistema Único de Saúde no Estado do Rio de Janeiro, Brasil. Cad Saúde Pública 2009; 25 Suppl 2:S269-78.

14. Brandão ER. Percepção do corpo feminino entre mulheres de camadas populares. In: Brandão ER, organizador. Saúde, direitos reprodutivos e cidadania. Juiz de Fora: Editora UFJF; 2000. p. 55-78.

15. Barbosa RM, Knauth DR. Esterilização feminina, AIDS e cultura médica: os casos de São Paulo e Porto Alegre, Brasil. Cad Saúde Pública 2003; 19 Suppl 2:S365-76.

16. Biroli F. Autonomia e justiça no debate sobre o aborto: implicações teóricas e políticas. Revista Brasileira de Ciência Política 2014; (15):37-68.

17. Villas Bôas B. População brasileira começa a encolher a partir de 2048, prevê IBGE. Valor Econômico 2018; 25 jul. https://www.valor. com.br/brasil/5686241/populacao-brasileiracomeca-encolher-partir-de-2048-preve-ibge.

18. Domingues RMSM, Silva CMFP, Grinsztejn BGJ, Moreira RI, Derrico M, Andrade AC, et al. Prevalência e fatores associados ao aborto induzido no ingresso em uma coorte de mulheres vivendo com HIV/aids, Rio de Janeiro, Brasil, 1996-2016. Cad Saúde Pública 2020; 36 Suppl 1:e00201318.
19. Lourenco GO, Amazonas MCLA, Lima RDM. Nem santa, nem puta, apenas mulher: a feminização do HIV/aids e a experiência de soropositividade. Sex Salud Soc (Rio J.) 2018; (30):262-81.

20. Fraga LS. A Aids no contexto de relações heterossexuais: decisões e práticas preventivas entre casais grávidos vivendo com HIV [Tese de Doutorado]. Rio de Janeiro: Escola Nacional de Saúde Pública Sergio Arouca, Fundação Oswaldo Cruz; 2019.

21. Secretaria de Vigilância em Saúde/Secretaria de Atenção à Saúde, Ministério da Saúde. Interrupção voluntária de gestação e impacto na saúde da mulher. https://www.jota.info/ wp-content/uploads/2018/08/312d26ded $56 \mathrm{~d} 74 \mathrm{e} 21 \mathrm{deec} 42 \mathrm{~b} 8 \mathrm{cf} 612 \mathrm{e} 8 . \mathrm{pdf}$ (acessado em $\mathrm{Mai} / 2019$ ).

22. Gómez-Suárez M, Mello MB, Gonzalez MA, Ghidinelli M, Pérez F. Access to sexual and reproductive health services for women living with HIV in Latin America and the Caribbean: systematic review of the literature. J Int AIDS Soc 2019; 22:e25273.

23. Knauth DR, Hentges B, Macedo JL, Pilecco FB, Teixeira LB, Leal AF. O diagnóstico do HIV/aids em homens heterossexuais: a surpresa permanece mesmo após mais de 30 anos de epidemia. Cad Saúde Pública 2020; 36:e00170118.

24. Zachek CM, Coelho LE, Domingues RMSM, Clark JL, De Boni RB, Luz PM, et al. The intersection of HIV, social vulnerability, and reproductive health: analysis of women living with HIV in Rio de Janeiro, Brazil from 1996 to 2016. AIDS Behav 2019; 23:1541-51.

25. Portella AP. Estratégias, desafios e limites na formação em gênero e saúde: reflexões a partir de uma experiência feminista. In: Villela W, Monteiro S, organizadores. Gênero e saúde: Programa Saúde da Família em questão. Rio de Janeiro: Associação Brasileira de Saúde Coletiva/Fundo de População das Nações Unidas; 2005. p. 155-66.

26. Cajado L, Monteiro S. Movimento social de mulheres com HIV/Aids: uma experiência entre cidadãs posithivas do Rio de Janeiro. Ciênc Saúde Colet 2018; 23:3223-32.

27. Villela W, Barbosa RM. Trajetórias de mulheres vivendo com HIV/Aids no Brasil. Avanços e permanências da resposta à epidemia. Ciênc Saúde Colet 2017; 22:87-96.

28. Rede Feminista de Saúde. Marcos da saúde das mulheres, dos direitos sexuais e direitos reprodutivos: ferramenta para a ação política das mulheres. https://edisciplinas.usp.br/plugin file.php/169650/mod_resource/content/2/ Texto\%20DDSSDDRR.pdf (acessado em 19/ Set/2018). 
Abstract

The article analyzes the views and practices on reproduction, sexuality, and rights of women living with HIV/AIDS (WLWA). This qualitative study was based on interviews at two moments, 2013 and 2018, with seven WLWA seen at HIV/AIDS referral services in Rio de Janeiro, Brazil. The study examined the opinions and experiences on motherhood, affective-sexual relations, feminism, and sexual and reproductive rights. The findings reveal the women's naturalized perception of the female body and their accountability on the events in sexual and reproductive life. An association was seen between reproductive right and the right to choose motherhood or the fathers' participation in raising the children. As for sexual rights, the prevailing conception was the woman's (or person's) right to choose in the face of demands, impositions, or violence to have sex, including the context of matrimonial relations. The sociocultural context proved to be more determinant in preventive practices and reproductive trajectory than HIV serology. WLWA displayed the capacity to reshape practices linked to routine care for the family, motherhood, contraceptive choices, and the exercise of sexuality. Yet traditional gender norms appear heavily in their family dynamics, and the reach of these transformations is mediated by the sociocultural and economic context. Thus, lower access to symbolic goods by low-income strata, which characterizes the universe of the women interviewed here, compromises their access to the gains made in sexual freedom and female autonomy.

\section{Reproductive Rights; Women; AIDS; Gender} and Health

\section{Resumen}

El artículo analiza las visiones y prácticas sobre reproducción, sexualidad y derechos de mujeres viviendo con VIH/sida (MVHA). El estudio, de carácter cualitativo, tuvo como base entrevistas realizadas en dos momentos, 2013 y 2018, con siete MVHA atendidas en servicios de referencia en $V I H / s i d a$ en Río de Janeiro, Brasil. Se investigaron opiniones y vivencias sobre maternidad, interacciones afectivo-sexuales, feminismo, derechos sexuales y reproductivos. Los hallazgos revelan la percepción naturalizada de las entrevistadas sobre el cuerpo femenino y su responsabilización acerca de los eventos de la vida sexual y reproductiva. Se nota una asociación entre derecho reproductivo y derecho de elección de la maternidad o de la participación de los padres en la crianza de los hijos. En cuanto a los derechos sexuales, prevaleció la concepción del derecho de elección de la mujer (o persona) ante las demandas, imposiciones o violencia para tener relaciones sexuales, incluyendo el contexto de las relaciones matrimoniales. La coyuntura sociocultural se mostró más determinante en las prácticas preventivas y trayectoria reproductiva que respecto a la serología del VIH. Se señaló la capacidad de las MVHA de remodelar prácticas relacionadas con la rutina de cuidado con la familia, maternidad, elecciones contraceptivas $y$ ejercicio de la sexualidad. Sin embargo, las normas tradicionales de género se muestran fuertemente en sus dinámicas familiares y el alcance de esas transformaciones es mediado por el contexto sociocultural y económico. Así, el menor acceso a bienes simbólicos de los estratos populares, que caracteriza el universo de las mujeres entrevistadas, compromete el acceso de estos grupos a conquistas relacionadas con la libertad sexual y autonomía femenina.

Derechos Sexuales y Reproductivos; Mujeres; SIDA; Género y Salud
Recebido em 16/Jun/2020

Versão final reapresentada em 30/Set/2020

Aprovado em 19/Out/2020 